\title{
Analysis of Jiang Zemin Thought in Science and Technology
}

\author{
Yanying Fei ${ }^{1, a}$, Wenhua Ren ${ }^{2, b}$ \\ ${ }^{1}$ Faculty of Humanities and Social Sciences, Dalian University of Technology, Dalian, China \\ ${ }^{2}$ School of Marxism, Dalian University of Technology, Dalian, China \\ a feiyanying@126.com, ${ }^{b} 1245144426 @ q q . c o m$
}

\begin{abstract}
Keywords: Technology innovation; Science and technology talents; Science and technology ethics. Abstract. In the 1990s, the global knowledge-economy has been booming, the traditional relationship between technology and the productivity was been rebuilt, and our technological power was urgently demanded to be built up. Under the condition, Jiang Zemin thought of science and technology emerged at a historic moment. Jiang Zemin thought in science and technology mainly includes view of science and technology productivity, view of technology innovation, view of science and technology talents and view of science and technology ethics, among which the view of technology innovation is the core content. In total, Jiang Zemin further enriches and develops Marxist theory of technology on the basis of inheritance of basic principles of Deng Xiaoping thought of science and technology.
\end{abstract}

\section{Introduction}

As the Party's third generation central leadership, Jiang Zemin gives a lot of brilliant exposition on problems in scientific and technical development. On the one hand, the formation of Jiang Zemin thought in science and technology is related to his background of science and engineering; On the other hand, it closely linked to the rising of knowledge-based economy and rebuilding of the traditional relationship between technology and the productivity. Jiang Zemin has fully recognized the importance of developing science and technology, pays close attention to the development process and profound implications on human society of science and technology revolution of the world.[1]

\section{The historical background of Jiang Zemin thought in science and technology}

2.1 The trend of global knowledge-based economy is overwhelming. Knowledge-economy was rising energetically as a new economy form since 1990s. Knowledge-economy refers to such an economic form, knowledge plays a more and more important role as a factor of production in economic life, the inputs of knowledge take over of traditional material resources, thus achieve the purpose of conserving material resources and improving economic efficiency. In other words, the original traditional economic with the main characteristic of huge consumption of raw material and energy is losing proper energy gradually, while a new economic form rely primarily on intellectual factor is flourishing. Meanwhile, along with entering the information society, integration of information technology and knowledge production shows great vitality. Therefore, most developed countries have already crossed the old industrial time which rely on financial capital to promote economic development, and gradually enter the era of knowledge economy. Knowledge achievements, especially new and high-tech achievements have already become independent productive factor, to some extent, can dominate the utilization of traditional resources and financial capital.

2.2 An upending of the relationship between traditional science and technology and productive forces. With further development of the revolution of science and technology, significant technical breakthroughs had a significant impact on human society. Science and technology play a more and more important role in productivity development, and the relationship between technology and productivity has been changed into a new relationship of Science-Technology-Production. Science and technology are not only the results of production practices, but also play a leading role in 
production practices. Today, grasping of the most advanced scientific achievements has becoming the standard of measuring a country's productivity. Therefore, science and technology is thought to be the most important driving force of the development of advanced productivity.

2.3 Building up our technological power is urgently needed. Since the mid-20th century, world science and technology has been developed rapidly, countries started to make new develop strategies. International high technology has become new competitive factor among major developed nations, in order to improve the comprehensive national power. Jiang Zemin calmly analyzes countries' situations in international community, and clearly indicates that "Some western countries pursue hegemonism and power politics without scruple, amassed most of wealth, capable of sustaining unfair and irrational international political and economic order, frequently threat and launch wars of aggression against weaker countries, it is because they take a leading position in science and technology, therefore seize economical and military advantage”. Accordingly, in order to gain the upper hand in international competition, we must highly value the development of science and technology, particularly develop domestic high and new advanced technology.

\section{The basic contents of Jiang Zemin thought in science and technology}

3.1 The relationship between technology and production: Science and technology becoming most main symbol of advanced productive force. Science and technology are of decisive significance for the advancement of human society, as it is key element of advancing construction of material civilization. It is Marxist viewpoint that science and technology are productivity; It is Deng Xiaoping's point of view that Science and technology are primary productive forces. On the basis of the viewpoint of Marx and Deng Xiaoping, Jiang Zemin further pointed out "Science and technology are the primary productive force and a concentrated reflection and a hallmark of advanced productive forces”. In his view, whether a productive force is advanced, what is important is how to produce, not what it produce or how many had been produced. Depends upon the science and technology, especially the technology adopt the latest high-tech achievements, are advanced productive forces. The above-mentioned important statements of Jiang Zemin pointed out the pivotal role and decisive function of science and technology in the development of productive forces, pointed the way forward in depending on science and technology to develop productivity.

3.2 The choice of scientific and technical development Strategy: Developing the country through science and education. Scholars have generally agreed that, the strategy of developing the country through science and education is an important content of Jiang Zemin thought in science and technology, which is also an important approach to implement the view of science and technology are the primary productive force. Jiang Zemin points out: "Preserve in the principle of education oriented, place science and technology and education in important position of national economic and social development, enhance the national technological strength and the ability of transforming science and technology into practical productive forces"[2]. The popularization of science and technology is the foundation of the reinvigorating strategy. To develop the National Economy by S.T. Progress, make the achievements of science and technology function properly in the development of productivity forces, it is necessary to disseminate and popularize the masses the latest development and new inventions in scientific field.

3.3 Problem of scientific and technical innovation: Innovation is the essential of science. Technological innovation is the core connotation of Jiang zemin thought in science and technology. [3]After the technology conference in 1995, technological innovation gradually become the most mentioned issue when he talked about problems with respect to science and technology. Jiang zemin states: "technological innovation should be vigorously pursued, promote self-innovation capability. No innovations, no development, no vitality." In his view, to conduct technological innovation, the aim is to enable science and technology to become formidable impelling force for China's cross-century development. Facing with this new revolution in science and technology worldwide, we must pay close attention to these major science and technology issues, which perform strategic, fundamental and crucial function to economic, technology, national defense and social development. 
Jiang zemin reiterated we should promote the construction of innovation system of state in china, set up our own innovation system, seek a road of Chinese science and technology innovation. To an extent, the science and technology system reform is the difficult and key point in our country's science and technology innovation development. To fulfill the purpose of Chinese scientific and technological structural reform, new type of science and technology management system should be established gradually, which can adapt to the socialist market economic system and the development rules of science and technology.

3.4 S\& T talents: The key of pushing forward the technological progresses and innovation is the talents. Jiang Zemin's new theory that "Human resources are first resources” is the inheritance and development of Marxist theory of talent resources. He has consistently held that technological advancements, economic boom and social development depend on improving the quality of workers. Scientists and technicians are the mainstay of socialist modernization and pioneer of new productive force. In August of 2001, he first proposed the theory that "Human resources are first resources" when attended a meeting held in Beidaihe. Jiang Zemin stressed that intellectuals are mainly engage in mental work among the working class, they play an indispensable role in our country's socialist modernization. Without the participation of intellectuals, victory on the reform is out of the question. In the practice of modernization construction and reform and opening cause, the government should put the intellectuals in an important strategic position, translate our country's human resources into qualified talent resource.

"Respecting knowledge and talented people" should be seen as an intrinsic element of the theory of "Human resources are first resources". "respect labor, respect knowledge, respect talent" is the core content of Deng Xiaoping talents theory, which is an important policy of building personnel team in new era, and also is the theoretical starting-point of the intellectual policies of the party. Jiang Zemin has always attached great importance to scientific and technological personnel, he holds that the talents are crucial factors that will determine success or failure of China science and technology development.[4] Jiang Zemin inherits and carries forward Deng Xiaoping talents theory, he affirms the position and function of intellectual in reform and opening up and socialist modernization, and emphasizes the full play of intellectuals' ability and wisdom in important decisions. To fully give out science and technology talents' function, Jiang Zemin requires party committees and governments at all levels should always trust and care for them, offer them suitable working and living conditions, and take effective measures to further promote the well prevailing custom of respect science, respect knowledge, respect talent.

3.5 Technology ethic: technical progress should serve humankind. Science and technology is a double-edged sword. Discoveries of science and technical inventiveness constantly have improved the production tools, have improved human understanding and transforming the nature, meanwhile, the negative effect of science and technology is increasingly appearing, the alienation of science and technology becomes more obvious.

When it comes to Human Genome Project, Jiang Zeming expounds the thoughts that Scientific development should serve humankind. He points out: "Human Genome Project is a great research project in life science history, it is meaningful for human being to understand itself and promoting the development of life sciences, medicine and pharmaceutical industry, Human genome sequence are the common wealth of human beings, they should serve humankind”. Technology ethic issues in 21st century will play a more and more predominant role, progress of science and technology should serve humankind, and should serve the lofty cause of world peace and development, not harm human life, which are the basic points of Jiang Zemin thought of technology ethic.

On the other hand, most Western nations have gradually completed changing from industrial society to informational society, while many developing countries have not completed industrialization yet. The benefits brought by industrial economy growth have been usurped by developed countries, but people in developing countries were not enjoying the benefits of industrial civilization. Based on this, stand on position the majority of developing countries, Jiang Zemin emphasizes that science and technology achievements should be used to escape many countries and their people from violence, ignorance and poverty, promote world peace and development. 


\section{Contemporary Value of Jiang Zemin science and technology thought}

4.1 Inherit and develop Marxist science and technology thought. Jiang Zemin science and technology thought, rich and develop the science and technology thought of Marx, Engels, Lenin, Mao Zedong and Deng Xiaoping under the new historical condition. Firstly, he develops this point that "Science and technology are part of the productive force". Science and technology is the primary productive force and a concentrated reflection and a hallmark of advanced productive forces, which are the enrichment and development of the point of 'Science and technology is part of the productive force'. Secondly, he objectively analyses the objective laws and external conditions of scientific and technological development, under the immature conditions of all-round development of mankind in our country, we should implement the strategy of developing the country through science and education, promote technological development through fostering scientific corps.

4.2 2. Supervise of China's practice in science and technology. Under the guidance of Jiang Zemin thought, major practical activities in the development of sciences and technology include: A talent team with a certain scale and rather high level established preliminarily ensure that the talents are younger in average age with further specialization; the government should reform the old personnel system, build a better policy and legal environment for the realization of the talents' self-worth; encourage the development of green technologies, dealing well with relationship between the development of science and technology and environmental protection, realize the sustainable development of society and economy.

\section{References}

[1] X.W. Tang, Research on Jiang Zemin's view of science and technology, Hunan Social Sciences, vol.02,2010,p.18-20

[2] Jiang Zemin, The theory of science and technology, edtied by Central Party Literature Press Publishing, 2001.

[3] S.T. Liu , Research on Jiang Zemin's thoughts of scientific and technological innovation, Theory and Reform, vol.03, 2008,p.28-31

[4] G.H. Li, Y.Y. Zhang, The connotation of Jiang Zemin's thought of scientific and technical personnel, Academic Forum, vol.09, 2011,p.33-36 